\title{
Species' traits and exposure as a future lens for quantifying seabird bycatch vulnerability in global fisheries
}

\author{
Cerren Richards ${ }^{1}$, Robert S. C. Cooke ${ }^{2-4}$, Diana E. Bowler ${ }^{5-7}$, Kristina Boerder ${ }^{8}$, Amanda E. \\ Bates ${ }^{1}$ \\ ${ }^{1}$ Department of Ocean Sciences, Memorial University of Newfoundland, St. John's, \\ Newfoundland, Canada \\ ${ }^{2}$ Department of Biological and Environmental Sciences, University of Gothenburg, Box 463, SE- \\ 405 30, Göteborg, Sweden \\ ${ }^{3}$ Gothenburg Global Biodiversity Centre, Box 461, SE-405 30, Göteborg, Sweden \\ ${ }^{4}$ UK Centre for Ecology \& Hydrology, Oxfordshire, OX10 8BB, United Kingdom \\ ${ }^{5}$ German Centre for Integrative Biodiversity Research (iDiv) Halle-Jena-Leipzig, Deutscher Platz \\ 5e, 04103 Leipzig, Germany \\ ${ }^{6}$ Friedrich Schiller University Jena, Institute of Biodiversity, Dornburger Str. 159, 07743 Jena, \\ Germany \\ ${ }^{7}$ Helmholtz-Center for Environmental Research - UFZ, Department Ecosystem Services, \\ Permoserstraße 15, 04318 Leipzig, Germany \\ ${ }^{8}$ Department of Biology, Dalhousie University, Halifax, Nova Scotia, Canada
}

Keywords: $\quad$ bycatch, longline, purse seine, IUCN red list, seabird, trait, trawl, threatened species, vulnerability, vulnerability framework

\begin{abstract}
Fisheries bycatch, the incidental mortality of non-target species, is a global threat to seabirds and a major driver of their declines worldwide. Identifying the most vulnerable species is core to developing sustainable fisheries management strategies that aim to improve conservation outcomes. To advance this goal, we present a preliminary vulnerability framework that integrates dimensions of species' exposure, sensitivity, and adaptive capacity to fisheries bycatch to classify species into five vulnerability classes. The framework combines species' traits and distribution ranges for 341 seabirds, along with a spatially resolved fishing effort dataset. Overall, we find most species have high vulnerability scores for the sensitivity and adaptive capacity dimensions. By contrast, exposure is more variable across species, and thus the median scores calculated within seabird families is low. We further find 46 species have high exposure to fishing activities, but are not identified as vulnerable to bycatch, whilst 133 species have lower exposure, but are vulnerable to bycatch. Thus, the framework has been valuable for revealing patterns between and within the vulnerability dimensions. Still, further methodological development, additional traits, and greater availability of threat data are required to advance the framework and provide a new lens for quantifying seabird bycatch vulnerability that complements existing efforts, such as the International Union for Conservation of Nature (IUCN) Red List.
\end{abstract}




\section{Introduction}

2 As of 2018, the global fishing fleet is estimated at 4.56 million fishing vessels of various sizes

3 (FAO 2020). Fisheries bycatch, the incidental mortality of non-target species, is a serious threat

4 to seabirds, driving seabird population declines worldwide (Dias et al. 2019). Thus, key goals for

5 successful fisheries management and conservation are to identify vulnerable non-target species

6 and develop bycatch mitigation strategies. Yet, these goals pose global challenges because

7 seabirds are wide ranging and encounter fishing activities in various national and international

8 waters at different stages of their life history (Komoroske and Lewison 2015). Better

9 understanding of the factors affecting vulnerability of species to bycatch is an essential step

10 towards predicting which species are most at risk and working to mitigate bycatch threats.

12 While seabird bycatch is widespread, a global quantification of seabird vulnerability to fisheries

13 bycatch in multiple gear types (e.g. longline, trawl and purse seine) is lacking because bycatch

14 data are scarce (Anderson et al. 2011, Hedd et al. 2016, Suazo et al. 2017, Zhou et al. 2019).

15 There is very low observer coverage aboard fishing vessels, and existing data has poor species

16 discrimination and only coarse quantification (Bartle 1991, Weimerskirch et al. 2000, Sullivan et

17 al. 2006, Anderson et al. 2011, Hedd et al. 2016, Suazo et al. 2017). Thus, bycatch mortality of

18 high-risk species may be undetected by on board vessels by fishers and observers, and therefore

19 under- or unreported to databases that collate species' threat data such as the International Union

20 for Conservation of Nature (IUCN) Red List (iucnredlist.org). Coupling traits with fisheries

21 exposure information could offer a complementary lens to existing methods and provide insights

22 into different dimensions of seabird bycatch vulnerability.

24 Trait-based approaches have emerged as being important for advancing conservation efforts

25 (Miatta et al. 2021), where traits represent fundamental biological attributes of organisms

26 measured at the individual level (Violle et al. 2007, Gallagher et al. 2020). Furthermore,

27 selecting ecologically meaningful and interpretable traits can relate to species' vulnerabilities to

28 threats (Zhou et al. 2019, Richards et al. 2021). As an exceptionally well-studied group, detailed

29 information is available on the life history, behavioural and ecological traits of seabirds for

30 predictive trait-based analyses (Tavares et al. 2019, Richards et al. 2021). Thus, integrating 
31 freely available global threat datasets with species traits in a vulnerability framework may be a

32 valuable tool to identify the seabird species most vulnerable to gear-specific bycatch.

34 A species' vulnerability to bycatch is determined by both extrinsic (threats) and intrinsic (traits)

35 factors. Specifically, such factors include the interplay between a species' exposure, sensitivity,

36 and capacity to adapt in response to bycatch (Foden et al. 2013, Potter et al. 2017, Butt and

37 Gallagher 2018). Firstly, exposure encompasses the extent to which species' ranges overlap with

38 fishing activities and the magnitude of activities experienced. For example, wide-ranging pelagic

39 foragers, such as albatrosses, overlap with a variety of fishing gears and fleets throughout their

40 lives (Clay et al. 2019). Secondly, sensitivity traits represent a species' likelihood of bycatch

41 mortality when it interacts with fisheries. For example, large seabirds have a greater risk of

42 bycatch mortality than smaller seabirds (Zhou et al. 2019). Finally, adaptive capacity traits

43 describe the ability for populations to adapt and recover from bycatch mortalities. For example,

44 bycatch will have a greater impact on seabirds with slow reproductive rates, such as albatross

45 and auks, which lay a single egg per season and reach sexual maturity after five to ten years.

47 Coupling a dataset of traits with seabird global range maps and a spatially resolved gear-specific

48 fishing dataset could provide a new lens for quantifying seabird bycatch vulnerability that would

49 complement existing efforts, such as the IUCN Red List. Here we (1) develop a framework for

50 quantifying seabird bycatch vulnerability to multiple gear types; (2) analyse the emerging

51 patterns of seabird bycatch vulnerability based on available data and traits; and (3) discuss future

52 directions and visions for the vulnerability framework.

\section{Building a vulnerability framework}

54 Here we modify a framework that has previously been applied to a diversity of species from

55 birds and trees to amphibians and corals (Foden et al. 2013, Potter et al. 2017), with the goal to

56 identify the seabird species most vulnerable to gear-specific bycatch (Fig. 1). Our intention is for

57 the vulnerability framework to be built upon and improved as more trait and threat data become

58 available in the future. 


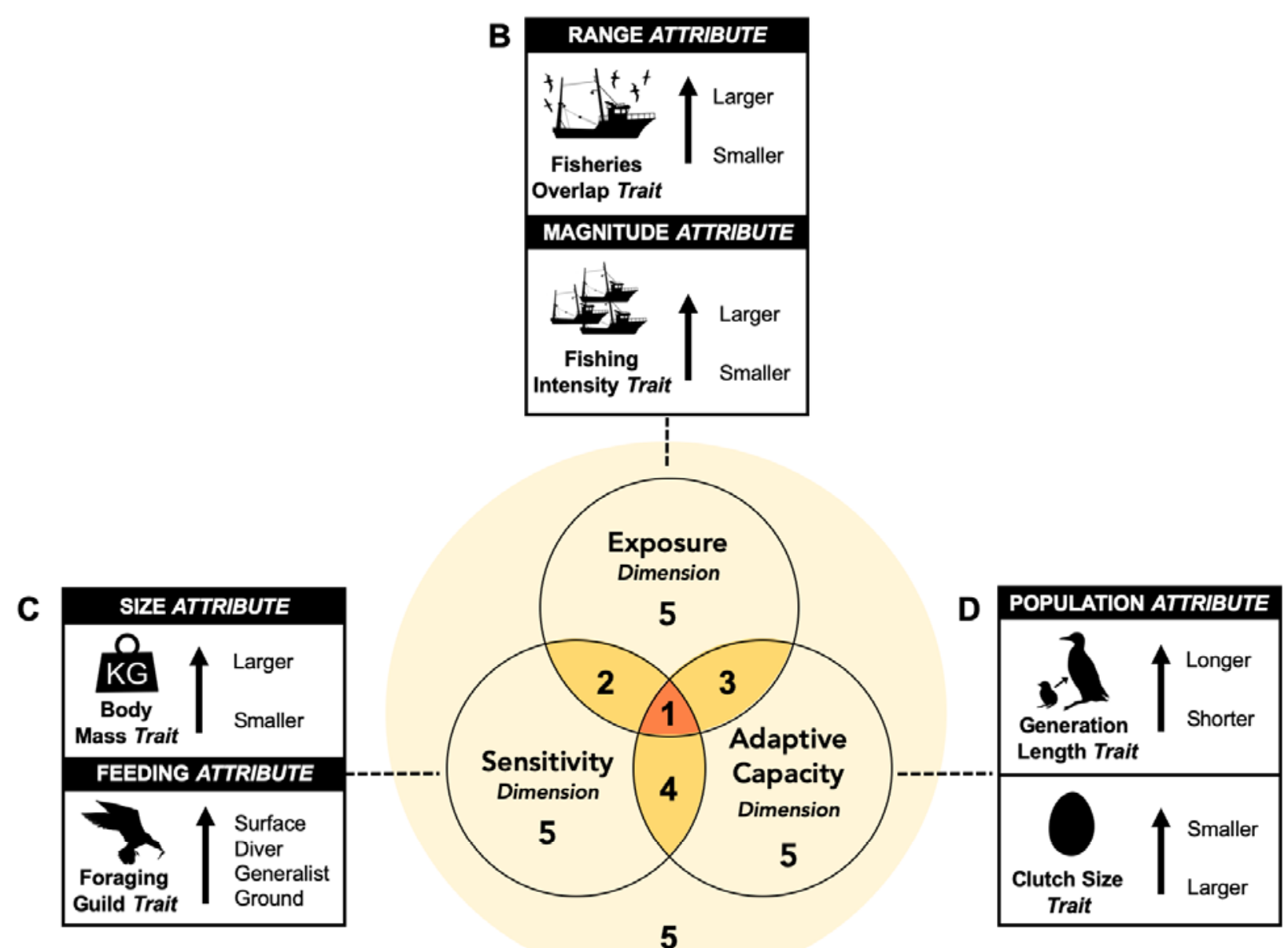

A SPECIES' VULNERABILITY CLASSES

62 Figure 1| Framework to quantify species' vulnerability to bycatch. The combination of

63 three dimensions: exposure, sensitivity and adaptive capacity, characterise five distinct species'

64 vulnerability classes (Box A). Six traits associated with five overarching vulnerability attributes

65 (Boxes B-D: Size, Feeding, Range, Magnitude, and Population) are used to quantify each

66 vulnerability class. Black arrows indicate the direction of increased vulnerability. Modified from

67 Foden et al. (2013) and Potter, Crane \& Hargrove (2017). 
70 The trait-based framework integrates three dimensions of bycatch vulnerability based on

71 exposure, sensitivity, and adaptive capacity. Each dimension encompasses a set of vulnerability

72 attributes (Size, Feeding, Range, Magnitude, Population) that in turn are represented by species'

73 traits (Fig. 1). The framework can be used to classify species into five vulnerability classes: high

74 vulnerability, potential adapters, potential persisters, potential future vulnerability, and low

75 vulnerability. Each has implications for conservation prioritisation and strategic planning (Foden

76 et al. 2013).

\section{Assessing sensitivity and adaptive capacity to bycatch}

79 We selected body mass and foraging guild to infer the framework's sensitivity dimension (Fig.

80 1C), and used generation length and clutch size to quantify the adaptive capacity dimension (Fig.

81 1D). All traits were extracted from a recently compiled dataset of seabird traits (Richards et al.

82 2021).

\section{Assessing exposure to bycatch}

85 To estimate the framework's exposure dimension, we quantified (1) overlap with fisheries

86 activities as the percentage of $1^{\circ}$ global grid cells shared between species' ranges and each gear-

87 specific fishing activity, and (2) fishing intensity as the sum of all fishing hours in the

88 overlapping grid cells (Fig. 1B). To achieve this, we first extracted distribution polygons for 341

89 seabirds (BirdLife International, 2017) which represent the coarse distributions that species

90 likely occupy, and are presently the best available data for the seabird global ranges. We created

91 a $1^{\circ}$ resolution global presence-absence matrix based on the seabird distribution polygons using

92 the package 'letsR' and function lets.presab (Vilela and Villalobos 2015). Second, we

93 downloaded the daily fishing effort data for longlines, trawls, and purse seines from Global

94 Fishing Watch, which classifies vessel activity based on vessel type and movements (Kroodsma

95 et al. 2018). For each gear type, fishing effort was summed per $1^{\circ}$ global grid cell between 2015

96 and 2018. Finally, to ensure consistency between the species' distribution and gear-specific

97 fishing activity layers, we re-projected all spatial data to a raster format with the same coordinate

98 reference system (WGS84), resolution $\left(1^{\circ} \mathrm{x} 1^{\circ}\right.$ global grid cells) and extent $\left( \pm 180^{\circ}, \pm 90^{\circ}\right)$. To

99 achieve this, we used the package 'raster' and function rasterize (Hijmans 2020). 


\section{Trait Scoring and Weighting}

102 Each trait, attribute and dimension were scored between 0 and 1, with 1 indicating the greatest

103 vulnerability to bycatch (Potter et al. 2017). This was achieved through a stepwise process. First,

104 all continuous traits from the vulnerability dimensions (body mass, clutch size, generation

105 length, overlap with fisheries, and fishing intensity) were broken into categories using the

106 Sturges algorithm which bins the traits based on their sample size and distribution of values

107 (Sturges 1926). All trait categories were then scored from high to low with ordinal variables

108 based on increased vulnerability to bycatch (Appendix 1-3). To ensure the prioritisation analysis

109 predictably weights the criteria (Mace et al. 2007), all scores were scaled between zero and one

110 and weighted by the frequency of trait occurrence (Potter et al. 2017).

112 The following worked example represents the scoring and weighting steps for a trait with four 113 categories:

115 Trait category 1 (lowest vulnerability) $=0$

116 Trait category $2=\left(\mathrm{n}_{1}+\mathrm{n}_{2}\right) / \mathrm{n}_{\text {total }}$

117 Trait category $3=\left(\mathrm{n}_{1}+\mathrm{n}_{2}+\mathrm{n}_{3}\right) / \mathrm{n}_{\text {total }}$

118 Trait category 4 (highest vulnerability) $=\left(\mathrm{n}_{1}+\mathrm{n}_{2}+\mathrm{n}_{3}+\mathrm{n}_{4}\right) / \mathrm{n}_{\text {total }}=1$

120 Where $\mathrm{n}$ is the number of species per trait category and $\mathrm{n}_{\text {total }}$ is the total number of species.

122 For example, foraging guild contains four categories: ground forager (category 1 = 13 species),

123 generalist forager (category $2=63$ species), diving forager (category $3=121$ species) and

124 surface forager (category $4=144$ species), and $\mathrm{n}_{\text {total }}$ for this study is 341 species. Ground forager

125 has the lowest conservation priority therefore is given a score of 0 . All other foraging strategies

126 are weighted proportionally based on the number of species within that category and the lower

127 categories (Potter et al. 2017). Therefore, generalist forager's score is $(13+63) / 341=0.22$,

128 diving forager's score is $(13+63+121) / 341=0.58$ and surface foragers, with the greatest 
conservation priority, have a score of $(13+63+121+144) / 341=1$. These equations are applied

130 to each trait independently, and the number of trait categories varies between 3 to 5 per trait.

\section{Vulnerability Classes}

133 We categorise species into vulnerability classes (Fig. 1A) based on a dimension score threshold 134 of 55\%. This threshold was decided from a sensitivity test by balancing between excluding all

135 vulnerable species because thresholds were too high, and ensuring minimal species changes

136 between threshold levels across all gear types (Fig. A4.1). If all dimensions (exposure,

137 sensitivity, and adaptive capacity) have a score greater or equal to 55\%, species are highly

138 vulnerable to bycatch, therefore, were classified into the "high vulnerability" class. If the scores

139 of sensitivity and exposure were greater or equal to $55 \%$, but adaptive capacity was less than

$14055 \%$, species were considered to have high vulnerability with potential adaptive capacity, and

141 were assigned to the "potential adapters" class. If the scores of adaptive capacity and exposure

142 were greater or equal to $55 \%$, but sensitivity was less than $55 \%$, species were considered to have

143 high vulnerability with potential to persist and were assigned to the "potential persisters" class.

144 Species were classified into the "potential future vulnerability" class if the scores of adaptive

145 capacity and sensitivity were greater or equal to 55\%, but exposure was less than 55\%. If all

146 dimensions have a score less than $55 \%$, or if only one dimension has a score greater or equal to

$14755 \%$, species had low overall vulnerability and were assigned to the "low vulnerability" class.

148 This approach was repeated for the three gear types (longline, trawl and purse seine). Thus, all

149 species received vulnerability scores and classes associated with each gear type.

151 All analyses were performed in R version 4.0.2 (R Core Team 2020).

\section{Emerging patterns of species' vulnerability to bycatch}

153 Our preliminary vulnerability framework revealed emerging patterns within the vulnerability

154 dimensions and classes, with species' vulnerability varying across the three gear types and

155 dimensions (Fig. 2 \& 3; Appendix 5). Albatrosses have the highest overall vulnerability followed

156 by frigatebirds, petrels, and shearwaters, while gulls, terns, and cormorants have the lowest 
157 overall vulnerability (Fig. 2). All seabird families have relatively high sensitivity (median $=0.70)$

158 and little capacity to adapt (median $=0.74$ ) in response to bycatch (Fig. 2). By contrast, exposure

159 is more variable and has emerged as an important vulnerability dimension. While the median

160 exposure across families is low (median =0.17; Fig. 2), a number of families and individual

161 species have high exposure scores. For example, the Wedge-tailed Shearwater

162 (Ardenna pacifica) has a longline exposure score of 0.95, the Northern Fulmar (Fulmarus

163 glacialis) has a trawl exposure score of 0.90, and the Black-tailed gull (Larus crassirostris) has a 164 purse seine exposure score of 0.97.

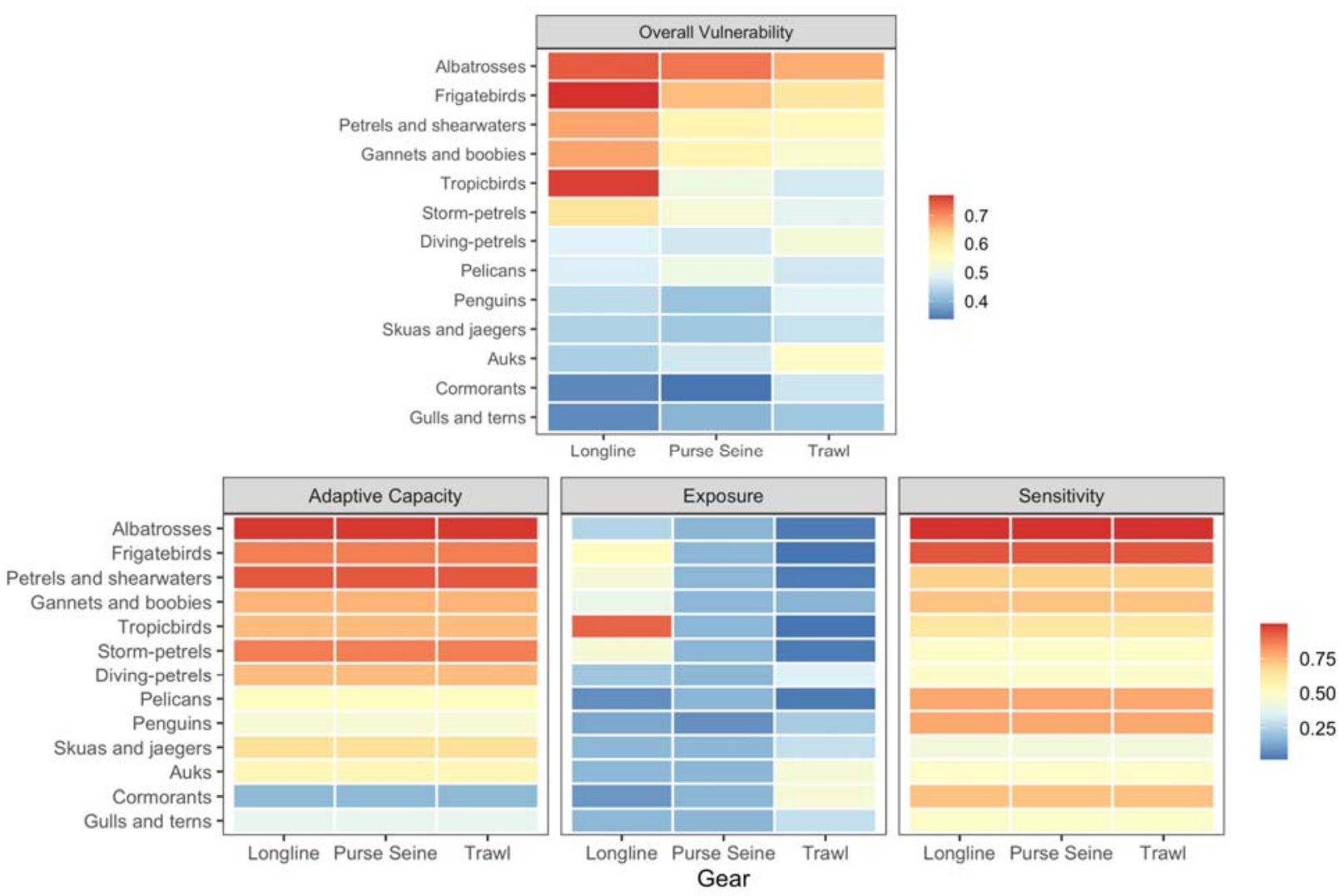

167 Figure 2 Median overall vulnerability, adaptive capacity, exposure, and sensitivity scores

168 of all seabird families to longline, purse seine, and trawl gear types.

170 Furthermore, we find 46 species have high exposure (score $\geq 75 \%$ ) to at least one gear type, but

171 are not identified as vulnerable to bycatch by the IUCN threat classification scheme (threats 5.4.3

$172 \&$ 5.4.4 from https://www.iucnredlist.org/resources/threat-classification-scheme). These species

173 were predominantly gulls and terns $(n=16)$, petrels and shearwaters $(n=13)$, and storm-petrels 
$174(\mathrm{n}=7)$. A total of 133 species have lower exposure (score $<75 \%)$ to at least one gear type, but 175 are identified as vulnerable to bycatch by the IUCN. These species were predominantly petrels 176 and shearwaters $(n=31)$, albatrosses $(n=22)$, auks $(n=19)$, and gulls and terns $(n=19)$.
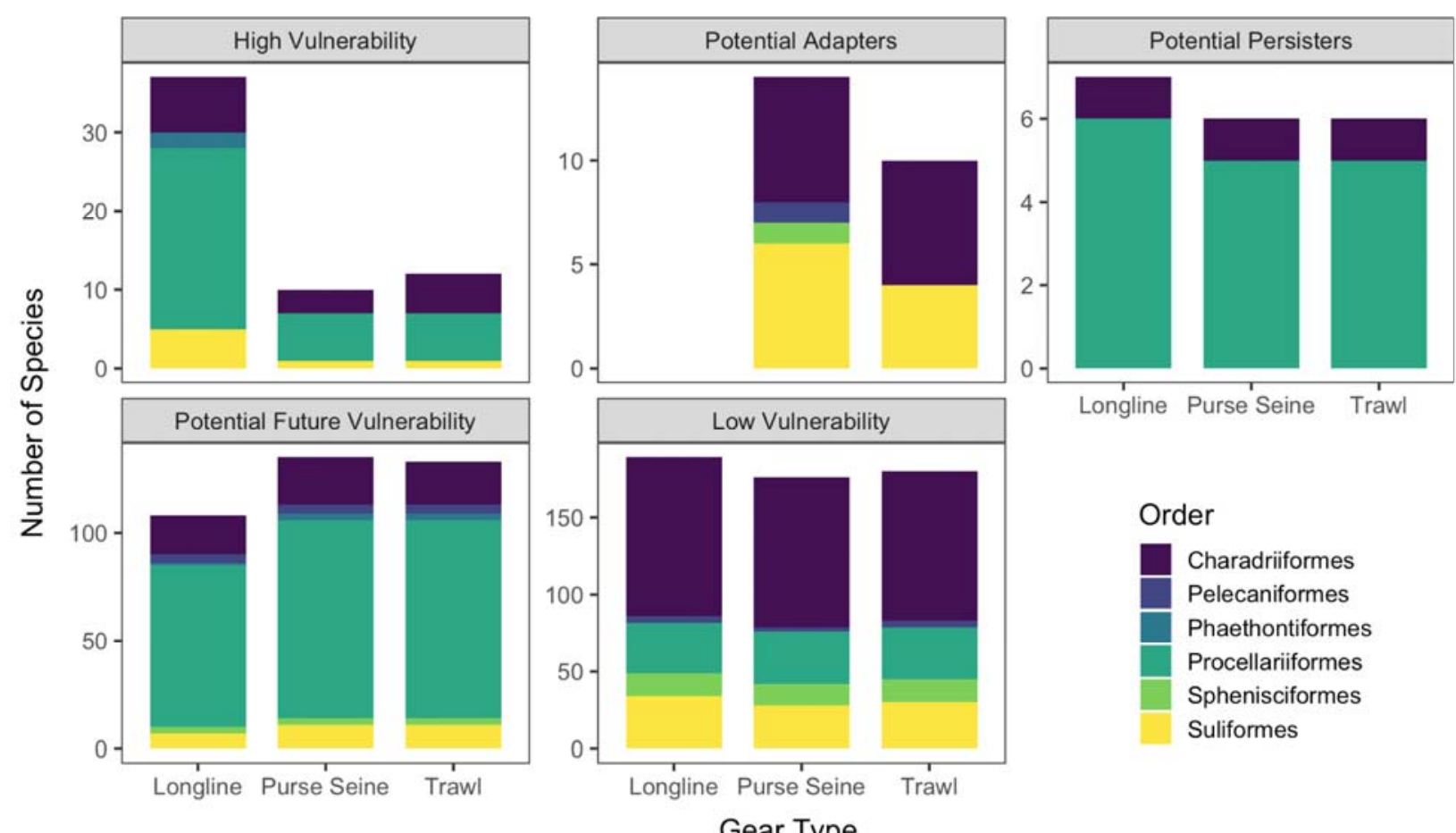

180 Figure 3 | The number of species falling into each vulnerability class for longline, purse

181 seine and trawl gear types. Charadriiforms encompass gulls, tern, skuas, auks, jaegers;

182 Pelecaniformes are pelicans; Phaethontiformes are tropicbirds; Procellariiformes encompass

183 albatross, petrels, shearwaters; Sphenisciformes are penguins; Suliformes encompass gannets,

184 boobies, cormorants, frigatebirds.

187 We further find taxonomic differences between the five vulnerability classes. Specifically, 188 species falling into the high vulnerability class (highest scores across all three dimensions) were 189 predominantly albatrosses, petrels, and shearwaters (Fig. 3; Appendix 5). The most frequent 190 species within the potential adapters class (high sensitivity and exposure scores, but do have 191 adaptive capacity due to low scores) were gulls and cormorants (Fig. 3; Appendix 5). Potential 192 persisters (low sensitivity score, high adaptive capacity and exposure scores) were typically 
193 storm-petrels and shearwaters (Fig. 3; Appendix 5). The potential future vulnerability class (high

194 scores for sensitivity and adaptive capacity, low score for exposure) was commonly composed of

195 albatrosses, petrels, and shearwaters (Fig. 3; Appendix 5). Finally, species classified with low

196 vulnerability (low scores across all dimensions, or a high score for only one dimension) were

197 predominantly gulls and terns (Fig. 3; Appendix 5).

\section{Vulnerability framework limitations}

199 The vulnerability framework identified $62 \%(n=32)$ more species that may be vulnerable to

200 bycatch (those falling into the high vulnerability class), but are not currently recognised by the

201 IUCN threat classification scheme as threatened from bycatch. Furthermore, it is important to

202 note that in its present form, the framework miss-classified 36\% $(\mathrm{n}=70)$ of the species identified

203 as threatened from bycatch by the IUCN into the low vulnerability class and $44 \%(\mathrm{n}=64)$ into

204 the potential future vulnerability class. These differences are likely attributed to limitations in

205 trait selection within the vulnerability framework's dimensions. For example, we do not include

206 a species' boldness or propensity to interact with vessels because these traits are not available for

207 all seabirds. To increase the framework's value, we encourage its further development in the

208 future with suggestions listed below.

\section{Future directions for the vulnerability framework}

210 While the framework has been valuable for revealing patterns between and within the

211 vulnerability dimensions, data limitations are presently impeding its full functioning to

212 effectively classify species into their vulnerability classes. However, we believe the framework

213 could become a valuable tool in the future as additional and finer-scale traits and threat data

214 become available because the framework is highly adaptable to spatial and temporal variations in

215 traits and threats. To aid in its replication and development in future analyses, we provide the $\mathrm{R}$

216 code used to build the framework.

218 Trait and dimension improvements

219 While an array of traits are available for seabirds, to strengthen the vulnerability framework's

220 dimensions, additional efforts are required to compile traits that are not currently available for all 
221 seabirds. For example, to improve the sensitivity dimension, future studies may include traits that

222 capture a species' likelihood of interacting with fishing vessels e.g., boldness, opportunism,

223 competitive ability, and whether they follow ships or not (e.g., Orben et al. 2021). To advance

224 the adaptive capacity dimension, adding additional metrics that relate to breeding and population

225 responses may be important, such as breeding frequency, productivity, and adult survival.

226 Finally, taking advantage of extensive seabird biologging data (e.g. seabirdtracking.org) will be

227 imperative to refine the spatiotemporal resolution of the exposure dimension, through shifting

228 the current fishing overlap metric to a quantification of fishing interaction rate. Moreover, adding

229 information on species abundance distributions and clustering behaviour may further improve

230 the exposure dimension.

232 Fishing activity data improvements

233 Fishing activity and seabird distributions vary daily, seasonally and annually. We therefore

234 acknowledge the limitation of using four years of aggregated fishing activity data. Future

235 modifications of the vulnerability framework may consider integrating the dynamic changes in

236 fishing activity. Moreover, including more gear types could further refine the approach. For

237 example, gillnets fisheries cause an estimated 400,000 seabird mortalities annually (Žydelis et al.

238 2013). However, we excluded this gear type from our analyses because it presently has poor

239 coverage within the Global Fishing Watch dataset. Finally, distributions of small-scale

240 subsistence, and illegal, unreported, and unregulated (IUU) fishing activities were unavailable,

241 and therefore not included in our vulnerability framework. Incorporating IUU fishing activities

242 in future studies could reveal species with unidentified vulnerability to bycatch.

\section{A future lens for conservation}

244 Few management actions have incorporated trait-based analyses into conservation strategies

245 (Miatta et al. 2021). However, we suggest that coupling species' traits with fisheries exposure

246 data within a vulnerability framework could offer an additional lens to advance ongoing

247 conservation measures and policy, such as the IUCN Red List. For example, there is very low

248 observer coverage aboard fishing vessels, and existing data has poor species discrimination and

249 only coarse quantification (Bartle 1991, Weimerskirch et al. 2000, Sullivan et al. 2006, Anderson

250 et al. 2011, Hedd et al. 2016, Suazo et al. 2017). Thus, bycatch mortality of high-risk species 
251 may be undetected by on board vessels by fishers and observers, and therefore unreported to the

252 IUCN. The framework could complement vessel-based observations through identifying

253 vulnerable species for which little is known e.g., revealing high vulnerability of gadfly petrels

254 (Pterodroma sp.) to longline fleets.

\section{Local management}

257 This framework could further be extended to inform local management actions. For example, the

258 framework can be easily updated based on interannual and seasonal variation in fishing activity,

259 additional gear types, and reapplied at local scales. We therefore highly recommend future

260 studies couple extensive seabird tracking data with colony-specific trait information and regional

261 fisheries patterns to provide a powerful and informative tool for local management.

\section{Conclusions}

263 We combined fine-scale fisheries data with seabird traits and distribution data to build a

264 preliminary vulnerability framework that has the potential to identify species at risk from

265 bycatch and help set conservation priorities. Overall, we find most species have high

266 vulnerability scores for the sensitivity and adaptive capacity dimensions. Yet, the framework

267 revealed that species' exposure to fisheries was highly variable, suggesting that vulnerability to

268 bycatch may be dynamic and rapidly change with future developments in fishing. The

269 framework is highly flexible to trait changes within each vulnerability dimensions, therefore we

270 recommend that future studies compile the additional traits that are required before the

271 framework can be used as a tool to classify species into the five vulnerability classes. Thus,

272 coupling species' traits with fisheries exposure data within a vulnerability framework could be

273 used as an additional lens to aid ongoing conservation measures and policy. For example,

274 through supporting the efforts of the IUCN Red List and threat identification by suggesting

275 which species need to be especially well investigated and protected.

\section{Data Sharing and Accessibility}

277 Seabird traits were extracted from (Richards et al. 2021), specifically

278 https://doi.org/10.5061/dryad.x69p8czhd. Species distribution polygons are available upon 
request from http://datazone.birdlife.org/species/requestdis. Fishing effort data for 2015 and 2016 are available for download, and data for 2017 and 2018 are available upon request from https://globalfishingwatch.org/. Please contact Cerren Richards (cerrenrichards@gmail.com) for

282 access to $\mathrm{R}$ code.

\section{Literature Cited} 2011. Global seabird bycatch in longline fisheries. Endangered Species Research 14:91-106. doi: 10.3354/esr00347.

Bartle, A. 1991. Incidental capture of seabirds in the New Zealand and sub-Antarctic squid trawl fishery, 1990. Bird Conservation International 1:351-359.

BirdLife International and Handbook of the Birds of the World. 2017. Bird species distribution maps of the world. Version 2017.2. http://datazone.birdlife.org/species/requestdis

Butt, N., and R. Gallagher. 2018. Using species traits to guide conservation actions under climate change. Climatic Change 151:317-332. doi: 10.1007/s10584-018-2294-z.

Clay, T. A., C. Small, G. N. Tuck, D. Pardo, A. P. B. Carneiro, A. G. Wood, J. P. Croxall, G. T. Crossin, and R. A. Phillips. 2019. A comprehensive large $\square$ scale assessment of fisheries bycatch risk to threatened seabird populations. Journal of Applied Ecology 56:1882-1893. doi: 10.1111/1365-2664.13407.

Dias, M. P., R. Martin, E. J. Pearmain, I. J. Burfield, C. Small, R. A. Phillips, O. Yates, B. Lascelles, P. G. Borboroglu, and J. P. Croxall. 2019. Threats to seabirds: A global assessment. Biological Conservation 237:525-537. doi: 10.1016/j.biocon.2019.06.033.

FAO. 2020. The State of World Fisheries and Aquaculture 2020. Sustainability in action. Rome.

Foden, W., S. H. M. Butchart, S. Stuart, J.-C. Vie', H. A. Resit, A. Angulo, L. M. DeVantier, A. Gutsche, E. Turak, L. Cao, S. D. Donner, V. Katariya, R. Bernard, R. A. Holland, A. F. Hughes, S. E. O'Hanlon, S. T. Garnett, C. H. Sekercioglu, and G. M. Mace. 2013. Identifying the World's Most Climate Change Vulnerable Species $\square$ : A Systematic Trait-Based Assessment of all Birds , Amphibians and Corals. PLOS ONE 8:e65427. doi: 10.1371/journal.pone.0065427.

Gallagher, R. V, D. S. Falster, B. S. Maitner, R. Salguero-gómez, V. Vandvik, W. D. Pearse, F. D. Schneider, J. Kattge, J. H. Poelen, J. S. Madin, M. J. Ankenbrand, C. Penone, X. Feng, V. M. Adams, J. Alroy, S. C. Andrew, M. A. Balk, L. M. Bland, B. L. Boyle, C. H. Bravo-avila, I. Brennan, A. J. R. Carthey, R. Catullo, B. R. Cavazos, D. A. Conde, C. A. Ray, M. Rossetto, H. Sauquet, B. Sparrow, M. J. Spasojevic, R. J. Telford, J. A. Tobias, C. Violle, R. Walls, K. C. B. Weiss, M. Westoby, I. J. Wright, and B. J. Enquist. 2020. Open Science principles for accelerating trait-based science across the Tree of Life. Nature Ecology \& Evolution 4:294-303. 
doi: 10.1038/s41559-020-1109-6.

Hedd, A., P. M. Regular, S. I. Wilhelm, J.-F. Rail, B. Drolet, M. Fowler, C. Pekarik, and G. J. Robertson. 2016. Characterization of seabird bycatch in eastern Canadian waters, 1998-2011, assessed from onboard fisheries observer data. Aquatic Conservation: Marine and Freshwater Ecosystems 26:530-548. doi: 10.1002/aqc.2551.

Hijmans, R. J. 2020. raster: Geographic Data Analysis and Modeling. R package version 3.3-13. https://CRAN.R-project.org/package=raster.

Komoroske, L. M., and R. L. Lewison. 2015. Addressing fisheries bycatch in a changing world. Frontiers in Marine Science 2:83. doi: 10.3389/fmars.2015.00083.

Kroodsma, D. A., J. Mayorga, T. Hochberg, N. A. Miller, K. Boerder, F. Ferretti, A. Wilson, B. Bergman, T. D. White, B. A. Block, P. Woods, B. Sullivan, C. Costello, and B. Worm. 2018. Tracking the global footprint of fisheries. Science 359:904-908. doi: 10.1126/science.aao5646.

Mace, G., H. Possingham, and N. Leader-Williams. 2007. Prioritizing choices in conservation. In: Macdonald D, Service K (eds) Key topics in conservation biology. Blackwell Publishing, Oxford.

Miatta, M., A. E. Bates, and P. V. R. Snelgrove. 2021. Incorporating Biological Traits into Conservation Strategies. Annual Review of Marine Science 13:421-443. doi: 10.1146/annurevmarine-032320-094121.

Orben, R. A., J. Adams, M. Hester, S. A. Shaffer, R. M. Suryan, T. Deguchi, K. Ozaki, F. Sato, L. C. Young, C. Clatterbuck, M. G. Conners, D. A. Kroodsma, and L. G. Torres. 2021. Across borders: External factors and prior behaviour influence North Pacific albatross associations with fishing vessels. Journal of Applied Ecology 00:1-12. doi: 10.1111/1365-2664.13849.

Potter, K. M., B. S. Crane, and W. W. Hargrove. 2017. A United States national prioritization framework for tree species vulnerability to climate change. New Forests 48:275-300. doi: 10.1007/s11056-017-9569-5.

R Core Team. 2020. R: A language and environment for statistical computing. R Foundation for Statistical Computing. https://www.r-project.org/.

Richards, C., R. S. C. Cooke, and A. E. Bates. 2021. Biological traits of seabirds predict extinction risk and vulnerability to anthropogenic threats. Global Ecology and Biogeography 30:973-986. doi: 10.1111/geb.13279.

Sturges, H. A. 1926. The choice of a class interval. Journal of the American Statistical Association 21:65-66.

Suazo, C. G., N. Oliveira, I. Debski, J. C. Mangel, J. Alfaro-Shigueto, J. Azocar, G. GarcíaAlberto, and E. Velarde. 2017. Seabird bycatch in purse seine fisheries: Status of knowledge and 
mitigation measures. ACAP - Eighth Meeting of the Seabird Bycatch Working Group.

Sullivan, B., T. Reid, and L. Bugoni. 2006. Seabird mortality on factory trawlers in the Falkland Islands and beyond. Biological Conservation 131:495-504. megafauna and their relationships with ecosystem functions and services. Frontiers in Marine Science 6:262. doi: 10.3389/fmars.2019.00262.

Vilela, B., and F. Villalobos. 2015. letsR: a new R package for data handling and analysis in macroecology. Methods in Ecology and Evolution 6:1229-1234. doi: 10.1111/2041-210X.12401.

Violle, C., M.-L. Navas, D. Vile, E. Kazakou, C. Fortunel, I. Hummel, and E. Garnier. 2007. Let the concept of trait be functional! Oikos 116:882-892. doi: 10.1111/j.2007.0030-1299.15559.x.

Weimerskirch, H., D. Capdeville, and G. Duhamel. 2000. Factors affecting the number and mortality of seabirds attending trawlers and long-liners in the Kerguelen area. Polar Biology 23:236-249. fisheries: Ecological traits matter. Aquatic Conservation: Marine and Freshwater Ecosystems 29:1324-1335. doi: 10.1002/aqc.3066.

Žydelis, R., C. Small, and G. French. 2013. The incidental catch of seabirds in gillnet fisheries: A global review. Biological Conservation 162:76-88. doi: 10.1016/j.biocon.2013.04.002. 